\title{
Synovial protease/inhibitor ratios in erosive and nonerosive arthropathies
}

\author{
M. H. PR I T C HAR D \\ From the Department of Rheumatology, University Hospital of Wales, Heath Park, Cardiff CF4 4XW
}

SUMMARY Although rheumatoid joint fluids contain numerous polymorphs capable of secreting neutral proteases known to be able to digest cartilage, the high level of inhibitors (mainly $\alpha_{1}$-antitrypsin and $\alpha_{2}$-macroglobulin) has always been considered to be more than sufficient to inhibit their activity completely. Consequently little interest has been paid to the potential role of these enzymes in cartilage damage. Four arthropathies of different erosive potential are here compared: spondyloarthropathies, rheumatoid arthritis with and without gold or D-penicillamine therapy, and septic arthritis. The synovial concentration of the inhibitors $\alpha_{1}$-antitrypsin and $\alpha_{2}$-macroglobulin has been compared with the polymorph enzyme output, as measured by $\beta$-glucuronidase. Total haemolytic complement, white cell count, and C-reactive protein have also been measured in the joint fluid. The range of white cell count and inhibitors was the same in all 4 groups, while the enzyme output varied substantially from low levels in the spondyloarthropathies to very high levels in the septic joints. The higher the erosive potential of the disease, therefore, the more disadvantageous is the inhibitor/enzyme ratic. It is also pointed out that cartilage has physiochemical properties which facilitate and enhance polymorph enzyme output while severely curtailing the activity of the inhibitors. The observation that synovial fluid is inhibitory in vitro may therefore bear little relationship to the situation at the cartilage surface in vivo.

The role of granulocyte neutral proteases and their relationship with their inhibitors in synovial fluid is still a matter of some controversy. In vitro, synovial fluid has an excess of inhibitors ${ }^{12}$ (mainly $\alpha_{1}$ antitrypsin $\left(\alpha_{1} \mathrm{AT}\right)$ and $\alpha_{2}$-macroglobulin $\left(\alpha_{2} \mathrm{MG}\right)$ ) over enzymes, yet there is no doubt that inflamed joints contain both macrophages and, in the fluid itself, very large numbers of polymorphonuclear leucocytes. These are capable of secreting into the extracellular medium a wide variety of neutral proteases which have been shown in vitro to be highly destructive to a variety of tissues, including cartilage $^{3-5}$ The presence of an erosive arthropathy implies that, if these enzymes have a similar effect in vivo, the inhibitors must be ineffective and the inhibitory excess in synovial fluid misleading. Conversely, if the inhibitor excess is genuine, the role of the enzymes is irrelevant to the progress of erosive arthropathies.

This concept, however, does not take into account the possibility that the inhibitors may be unevenly distributed in vivo, with some localities in the joint cavity being relatively deficient. Synovial microenviron-

Accepted for publication 11 January 1983.

Correspondence to Dr M. H. Pritchard. ments have been discussed by Dingle ${ }^{1}$ in relation to pannus, where enzymes can be detected in in an active state, and there are theoretical reasons (discussed later in this paper) why the surface of cartilage should also be considered as a microenvironment in which protease inhibitors are at a substantial disadvantage.

In this study inhibitor concentrations in a wide variety of joint fluids were compared with polymorph neutral protease secretion, as measured by synovial $\beta$-glucuronidase ( $\beta$-gluc), with the object of comparing the inhibitor and enzyme ratios in a variety of erosive and nonerosive situations.

\section{Materials and methods}

Synovial fluid was aspirated from the knees of 110 patients attending the Rheumatology Outpatient Clinic with a chronic inflammatory arthritis. The fluid was aspirated by normal aseptic techniques and transported to the Rheumatology Laboratory within 2 hours in a sterile glass container. $1 \mathrm{ml}$ was heparinised for a total white cell count The main sample was centrifuged and the clear supernatant stored at $-20^{\circ} \mathrm{C}$. 
Patients were categorised according to their diagnosis and drug therapy. All patients were taking nonsteroidal anti-inflammatory drugs (NSAIDs); 10 rheumatoid patients were also taking prednisone in doses of between 5 and $7.5 \mathrm{mg}$ daily. This did not have any obvious effect on any parameter measured and has not been considered separately. The categories were as follows: (1) patients with rheumatoid arthritis (RA) taking NSAIDs alone, 49; (2) RA currently being treated with gold or penicillamine in addition to NSAID therapy, 27 patients; (3) spondyloarthropathies and reactive arthritis, 22 patients; (4) septic arthritis, 6 patients.

Joint fluids containing less than $3500 / \mathrm{mm}^{3}$ white cells $\left(3.5 \times 10^{9} / 1\right)$ were not considered to be inflammatory and were excluded. The patients with septic arthritis were too few for accurate statistical analysis but were of interest on an individual basis. Two patients had severely purulent joints, the other 4 had early mild infection only. Tests fell into 3 categories: general, inflammatory, and enzymatic.

General. Total haemolytic complement $(\mathrm{CH} 50)^{6}$ (as adapted by ourselves for routine use) was measured in every sample. Sheep red cells were obtained fresh once a fortnight and immediately after venesection were put into Alsever's medium. Antisheep haemolysin was obtained from Difco Ltd and guinea-pig complement for standardisation from Gibco.

Synovial fluid total protein was measured by estimating the absorption at $280 \mathrm{~nm}$ on an ultraviolet spectrophotometer with the use of pooled inflammatory synovial fluid of known protein concentration as a standard. The total white cell count was measured manually in a cell-counting chamber.

Inflammatory. Nine protease inhibitors are detectable in serum, ${ }^{7}$ all produced in the liver, and these presumably cross the synovial barrier. $\alpha_{1} \mathrm{AT}$ is present in the serum in approximately 10 times the molecular concentration of any of the others, so $\alpha_{1} \mathrm{AT}$ and $\alpha_{2} \mathrm{MG}$ were considered to be representative of the wide range of inhibitors that should be present in synovial fluid. Both were measured by electroimmunoassay. ${ }^{8}$

A standard curve was obtained from a series of dilutions of pooled normal serum which had been given an arbitrary figure of 100 units for both inhibitors, and all results were estimated relative to this. The pooled normal serum was obtained from healthy volunteers, divided into aliquots, and deep frozen. Random checks from time to time showed the concentrations of $\alpha_{1} \mathrm{AT}$ and $\alpha_{2} \mathrm{MG}$ in the serum to be consistent.

C-reactive protein (CRP) was also measured by electroimmuno assay in 37 synovial fluid specimens without regard to the diagnosis. To ensure sufficient mobility on the agarose plate each sample was carbamylated by prior incubation with 3 volumes of 1.5 $\mathrm{M} \mathrm{KCNO}$ at $40^{\circ} \mathrm{C}$ for 1 hour.

Enzymatic. Proteolytic enzyme activity was measured by estimating $\beta$-gluc. ${ }^{9}$ The phenolphthalein released from the hydrolysis of phenolphthalein glucuronide (Sigma) was estimated at $550 \mathrm{~nm}$ on a Unicam SP600 spectrophotometer against a standard curve and results expressed in Sigma units.

\section{Results}

Fig. 1 shows the wide scatter of white cell counts found in 3 major categories - namely, spondyloarthropathies, rheumatoid arthritis (gold or penicillamine), and rheumatoid arthritis (NSAIDs). Differential white cell counts have shown that well over $90 \%$ of the cells were polymorphs. The wide scatter of results in each of the 3 main groups presumably reflects the wide range of clinical activity, but the

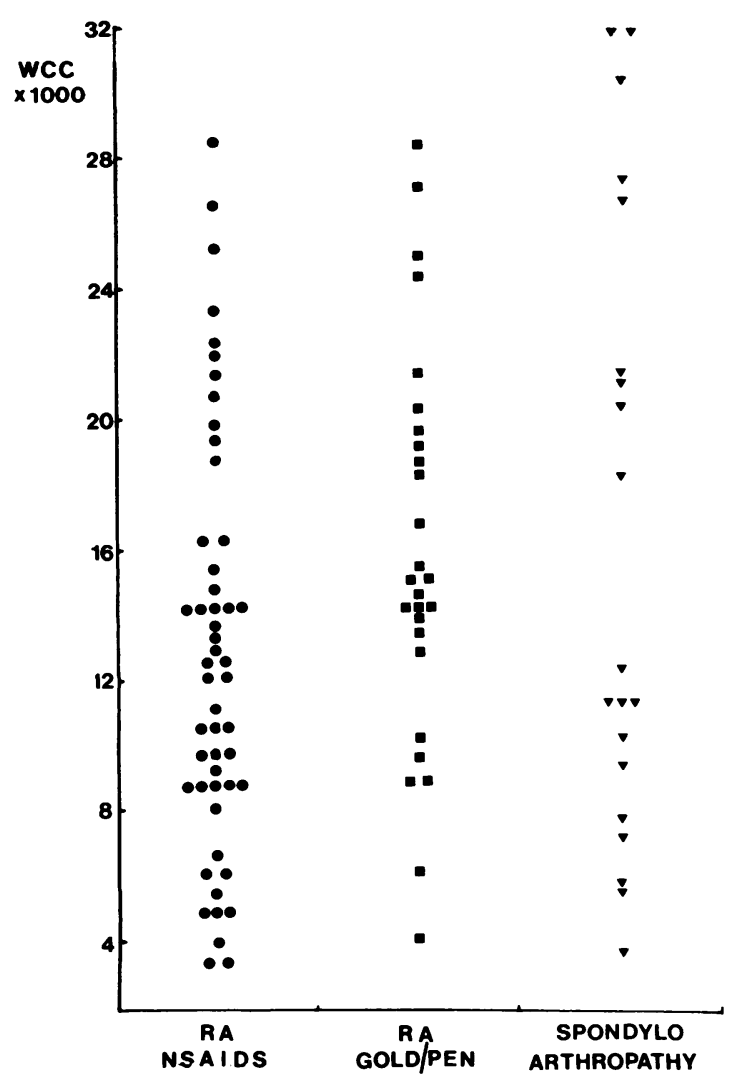

Fig. 1 Distribution of synovial white cell counts (WCC) in the 3 main groups. 
Table 1 Mean \pm standard deviation: pooled normal serum $=100$

\begin{tabular}{lllrr}
\hline & Spondyloarthritis & $\begin{array}{l}R A \\
\text { gold/pen }\end{array}$ & $\begin{array}{l}\text { RA } \\
\text { NSAID }\end{array}$ & \multicolumn{1}{l}{$\begin{array}{l}\text { Septic } \\
\text { arthritis }\end{array}$} \\
\hline$\alpha_{1}$ AT & $109 \pm 27$ & $115 \pm 35$ & $121 \pm 40$ & $116 \pm 25$ \\
$\alpha_{2}$ MG & $61^{*} \pm 29$ & $45^{*} \pm 21$ & $49 \pm 18$ & $39 \pm 12$ \\
\hline
\end{tabular}

*p $<0.05$.

All results relative to pooled normal serum $=100$.

range is similar in each of the 3 groups and there is no significant difference between the mean values.

Table 1 shows the synovial $\alpha_{1} \mathrm{AT}$ and $\alpha_{2} \mathrm{MG}$ results. There is no significant difference between the $\alpha_{1}$ AT levels in any of the 4 groups, including the septic arthropathies, whereas the $\alpha_{2}$ MG levels are not only surprisingly low in all groups but show wide differences. Part of the explanation for this may be due to the observation that almost all the $\alpha_{2} \mathrm{MG}$ is complexed with enzymes in rheumatoid synovial fluid. ${ }^{10}$ Ekerot has shown that complexed $\alpha_{2}$ MG moves differently in agarose on electroimmunoassay, resulting in a $20 \%$ shortening of the rocket height. ${ }^{10}$

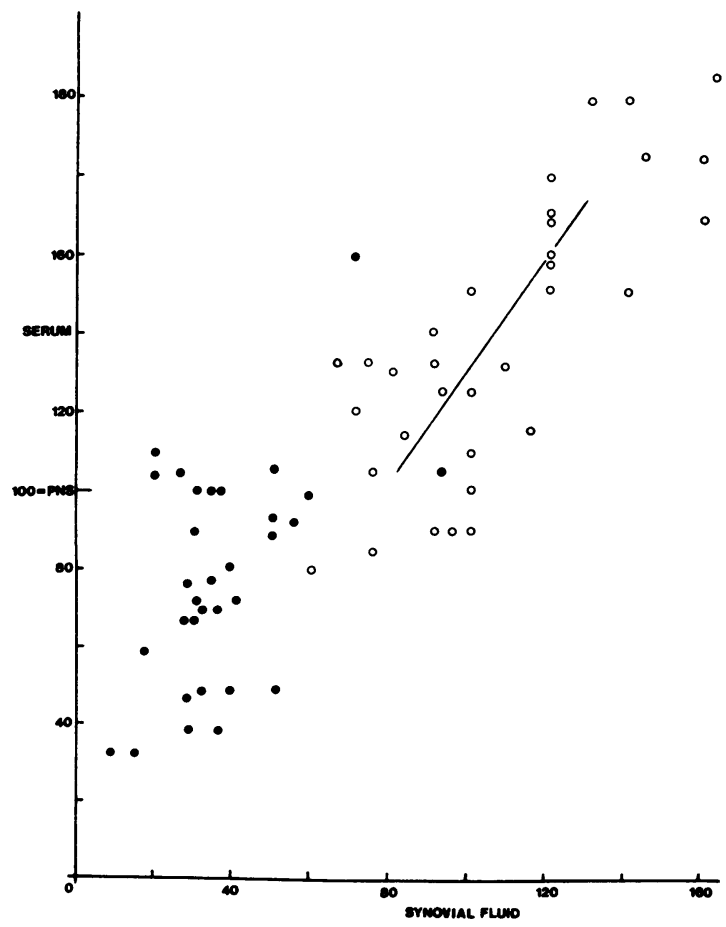

Fig. 2 Serum and synovial fluid $\alpha_{1} A T(O)$ and $\alpha_{2} M G(0)$.
Fig. 2 shows a scatter diagram between serum and synovial fluid levels of $\alpha_{1} \mathrm{AT}$ and $\alpha_{2}$ MG in 33 unselected paired specimens. $\alpha_{1}$ AT correlates very closely between the serum and synovial fluid, and in all except 2 specimens the higher level is in the serum $(\mathrm{r}=0.83, \mathrm{p}<0.001)$. There is a much weaker correlation between serum and synovial fluid $\alpha_{2} \mathrm{MG}(\mathrm{r}=0 \cdot 4$, $\mathrm{p}<0.05)$. The conclusion is that both inhibitors are produced in the liver rather than locally and reach the joint by simple diffusion through the synovial membrane. The mean serum $\alpha_{1}$ AT level compared with the mean synovial fluid level shows that approximately $70 \%$ of the protein gets into the synovial fluid, whereas a similar comparison between the $\alpha_{2} \mathrm{MG}$ readings shows that less than $40 \%$ reaches the fluid. The differences are presumably due to the different sizes of the 2 molecules. $\alpha_{2} \mathrm{MG}$ has a molecular weight of 900000 , and penetration is therefore much more dependent on the degree of inflammation of the synovial membrane.

Synovial fluid $\alpha_{1} \mathrm{AT}$ was also correlated with $\mathrm{C}$-reactive protein in 37 synovial fluids taken without reference to the diagnosis. A significant correlation between the 2 was seen $(r=0.56, p<0.001)$ suggesting that these 2 both enter the synovial fluid from the serum with approximately equal ease. There was no correlation between $\alpha_{1} \mathrm{AT}$ and $\alpha_{2} \mathrm{MG}$ either in the serum or in the synovial fluid. The stimulus for $\alpha_{2} \mathrm{MG}$ production appears therefore to be different from that of $\alpha_{1} \mathrm{AT}$ and CRP.

Table 2 shows the mean and standard deviation of the total haemolytic complement $(\mathrm{CH} 50)$ in the synovial fluid together with the synovial $\beta$-gluc. The latter showed no relationship with serum levels in any of the paired samples taken. The $\mathrm{CH} 50$ results were similar to those published previously. ${ }^{11} \beta$-gluc results show that there was a 3 -fold increase in proteolytic enzyme secretion in the joints of the rheumatoid arthritic patients compared with the spondyloarthritic ones, and that in the presence of gold or penicillamine there was a substantial modification of this

Table 2 Mean \pm standard deviation

\begin{tabular}{|c|c|c|c|c|}
\hline & $\begin{array}{l}\text { Spondylo- } \\
\text { arthropathy }\end{array}$ & $\begin{array}{l}\text { RA } \\
\text { gold/pen }\end{array}$ & $\begin{array}{l}R A \\
N S A I D\end{array}$ & $\begin{array}{l}\text { Septic } \\
\text { arthritis }\end{array}$ \\
\hline CH50 & $\begin{array}{l}19 \cdot 3^{*} \pm 4 \cdot 8 \\
(\text { Normal serum }\end{array}$ & $\begin{array}{l}13 \cdot 0 \pm 8 \cdot 0 \\
28-32 \text { units) }\end{array}$ & $8 \cdot 9^{*} \pm 2 \cdot 8$ & - \\
\hline $\begin{array}{l}\beta \text {-gluc } \\
\text { Range }\end{array}$ & $\begin{array}{l}20 \cdot 7^{*} \pm 5 \cdot 9 \\
9-28\end{array}$ & $\begin{array}{l}40 \cdot 4^{*} \pm 24 \cdot 0 \\
11-106\end{array}$ & $\begin{array}{l}56 \cdot 0^{*} \pm 36 \cdot 0 \\
11-165\end{array}$ & $\begin{array}{l}606 \pm 763 \\
123-1884\end{array}$ \\
\hline
\end{tabular}

Correlation between $\mathrm{CH} 50$ and $\beta$-glucuronidase: $\mathrm{r}=-0 \cdot 36^{*}$. *p $<0.05$.

One CH50 unit will lyse $50 \%$ of $5 \times 10^{8}$ sheep red cells. 


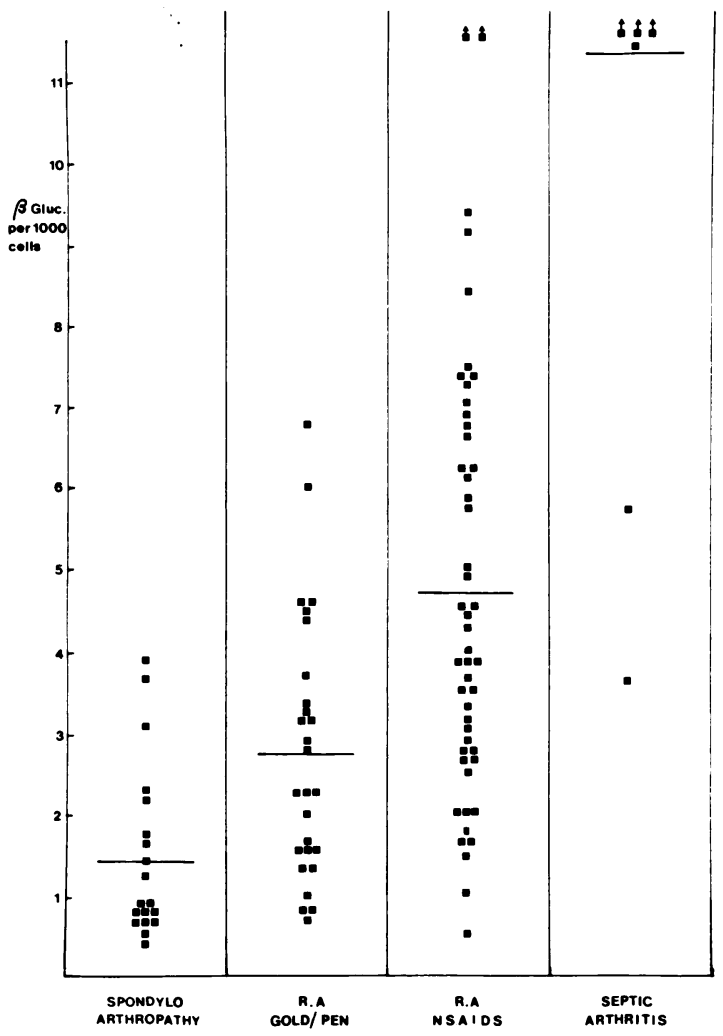

Fig. 3 B-gluc output per 1000 white cells in synovial fluid.

enzyme secretion. The septic arthritic group showed the extreme levels which could be reached by polymorph enzyme secretion without equivalent rises in inflammatory parameters. That this was more dependent on polymorph activity than numbers is shown in Fig. 3, where the $\beta$-gluc level per 1000 polymorphs is tabulated. The mean is significantly different in each group.

By comparing the 3 groups it is clear that high complement consumption-i.e., low $\mathrm{CH} 50$ levels-was accompanied by increased levels of enzyme secretion and vice versa. It is reasonable to deduce from this that the presence of large complexes of IgG in the joint fluid was directly influencing both parameters, since Henson ${ }^{12}$ has shown that the bigger the complex the more $\beta$-gluc is secreted during phagocytosis.

In summary, therefore, the inflammatory parameters in each group remained the same while the enzyme secretion was highly variable. The inflammatory response was clearly a systemic manifestation, while the enzyme production and complement
Table $3 \beta$-glucuronidase $/ \alpha_{1}$-antitrypsin ratios: mean \pm standard deviation

\begin{tabular}{lllll}
\hline $\begin{array}{l}\text { Spondylo- } \\
\text { arthropathies }\end{array}$ & $\begin{array}{l}\text { RA } \\
\text { gold/pen }\end{array}$ & $\begin{array}{l}\text { NA } \\
\text { NSAID }\end{array}$ & \multicolumn{2}{c}{ Septic arthritis } \\
\cline { 3 - 5 } & & Mild & Purulent \\
\hline $0 \cdot 20^{*} \pm 0 \cdot 05$ & $0 \cdot 39^{*} \pm 0 \cdot 29$ & $0 \cdot 52^{*} \pm 0 \cdot 33$ & $1 \cdot 1$ & $15 \cdot 7$ \\
\hline
\end{tabular}

${ }^{*} \mathrm{p}<0.05$.

consumption were local events related only to a single joint. The 2 sets of parameters appeared to be entirely independent of each other.

The relative activities of these 2 observations-that is, inflammatory response and enzyme production-can be expressed in each individual joint as a ratio. The results are shown in Table 3 . This ratio is significantly different in each of the 4 groups, and the higher ratios are associated with the increased potential destructiveness of the disease process.

\section{Discussion}

The 4 types of arthropathies studied in this paper cover the full range of erosive potential. Spondyloarthropathies are generally (although not invariably) nonerosive. Gold and penicillamine are usually considered to modify the erosive potential of rhe umatoid disease, and septic arthropathies are highly destructive in a short space of time. The polymorph proteolytic enzyme output, as measured by $\beta$-gluc, is low in the spondyloarthritic group and extremely high in the septic group. The 2 rheumatoid groups are in between. In spite of this rise in enzyme output the inflammatory response, as measured by the white cell count, $\alpha_{1} \mathrm{AT}$ and $\alpha_{2} \mathrm{MG}$, is almost the same in all 4 groups. and the $\alpha_{2} \mathrm{MG}$ is in fact surprisingly low in the rheumatoid groups compared with the others. The small numbers of paired samples available show that this low level of $\alpha_{2} \mathrm{MG}$ is also seen in some rheumatoid sera. The ratio of enzymes to inhibitors, therefore, in the joint fluid becomes steadily more disadvantageous as the erosive potential of the disease increases.

Synovial fluid, however, is highly inhibitory to proteases, and this has led Hadler et al. ${ }^{2}$ to cast doubt on Zvaifler's original hypothesis that polymorph lysosomal enzymes in synovial fluid are primarily involved in articular destruction. ${ }^{3}$ If synovial fluid is always inhibitory, then the enzyme/inhibitor ratios measured in this paper, even though widely different, may not be of much relevance.

However, there is no way of proving that synovial fluid is homogeneous in vivo, and it is possible that the relationship between proteases and inhibitors 
may vary considerably in different parts of the joint. This is certainly so in cartilage covered by pannus. Dingle $^{1}$ has demonstrated cathepsin-D in high concentration in an area of pannus-covered erosion in human rheumatoid cartilage, and suggested that fluid-based inhibitors could have little effect on such an environment. He also pointed out that there were 3 main sources of enzymes capable of degrading cartilage. These were the synovium and associated pannus, the chondrocytes themselves-whose activity appeared to be related to the presence of a synovial catabolic factor-and the synovial fluid. Like Hadler he considered that fluid-based enzymes were unlikely to be important because of the high fluid inhibitor concentration.

It is a common observation during a surgical operation to see areas of cartilage eroded at a considerable distance from the leading edge of the pannus. This would suggest that other mechanisms apart from synovium or pannus-based products are likely to be responsible, and this in turn suggests that fluid-based mechanisms may after all be important. There are several reasons why bare cartilage surface, as opposed to that covered by pannus, should be considered as a microenvironment with its own special properties where proteases and inhibitors are concerned. These are discussed below.

Henson $^{12}$ showed that, although polymorphs release lysosomal enzymes in response to a number of stimuli, by far the most powerful stimulus is the presence of immune complexes or aggregates attached to solid surfaces. Enzyme release in this situation is highly specific and does not require cell destruction. He found that only $1 / 15$ th of the amount of immune complex is required to stimulate a given amount of $\beta$-gluc when it is attached to a solid surface in contrast to when the material is floating freely in the medium. Immune complexes, therefore, attached to the surface of the cartilage are a highly potent stimulant to local enzyme production and would ensure a much higher enzyme output in the immediate vicinity of the cartilage than would be seen in the fluid itself. There is no doubt that rheumatoid cartilage is extensively covered with immune complexes. In a study of biopsy specimens from cartilage surfaces Cooke et al. ${ }^{13}$ demonstrated their presence by immunofluorescence in 34 of 37 rheumatoid samples. The control group (mainly patients undergoing meniscectomy) did not show any such deposition. The immunofluorescence was particularly heavy around areas of local damage.

The proteoglycans in cartilage matrix are negatively charged due to the carboxyl and sulphate radicals attached to the glycosaminoglycan residues. This fixed charge is neutralised by freely diffusable cations. ${ }^{14}$ Elastase and other proteolytic enzymes are small, strongly positively charged proteins able to diffuse into cartilage quickly and easily. ${ }^{15}$ Maroudas ${ }^{14}$ has shown that the diffusion of molecules into cartilage depends on size as well as charge, and considers that 60000 is the upper limit for cartilage penetration. $\alpha_{1} \mathrm{AT}$ has a molecular weight of 60000 and is strongly negatively charged. $\alpha_{2}$ MG has a molecular weight of 900000 and is also strongly negatively charged. In addition to exclusion by size, therefore, there is an electrostatic repulsion between cartilage and protease inhibitors which may be strong enough to prevent the inhibitors from even approaching the cartilage surface closely. Ugai et al. ${ }^{16}$ have shown in vitro that polymorphs could penetrate several cell diameters below the articular surface-although they have not found this in rheumatoid joints themselves. In such an environment the cells would be virtually immune from the effect of protease inhibitors.

Thirdly, James and Cohen ${ }^{17}$ have shown that 2 possible reactions can take place between $\alpha_{1} \mathrm{AT}$ and elastase. The first of these involves the formation of a stable complex in which the elastase is inhibited by the $\alpha_{1} \mathrm{AT}$, but they have also observed that elastase can hydrolyse $\alpha_{1} \mathrm{AT}$, inactivating the latter but leaving the enzyme still active. Even at high inhibitor excess both reactions take place equally, and 2 molecules of $\alpha_{1} \mathrm{AT}$ are required to inactivate 1 molecule of elastase.

The fourth disadvantage for the inhibitors is the relative inability for $\alpha_{2} \mathrm{MG}$ to penetrate the synovial membrane and enter the joint fluid. Although it has been shown that it can be produced by local macrophages, ${ }^{18}$ the serum/synovial fluid ratios reported here suggest that systemic production-that is, in the liver-is by far the most important contributor. The importance of $\alpha_{2} \mathrm{MG}$ can be surmised from the work of Ekerot. ${ }^{10} \mathrm{He}$ has shown that it is almost entirely complexed in the joint fluid, whereas $\alpha_{1} \mathrm{AT}$ is almost completely in the free state, It is possible, therefore, that $\alpha_{1} \mathrm{AT}$ and $\alpha_{2} \mathrm{MG}$ work in conjunction to some extent, the former acting as a carrier temporarily inactivating the protease before transferring it to $\alpha_{2} \mathrm{MG}$ for permanent inactivation and disposal. Ohlsson and Laurell ${ }^{19}$ have shown that this relationship exists in the serum of dogs injected with active enzymes. If $\alpha_{2} \mathrm{MG}$ is saturated, it is no longer capable of accepting further enzymes from $\alpha_{1} \mathrm{AT}$, and the concentration and degree of saturation of $\alpha_{2} \mathrm{MG}$ becomes the rate-governing step in the permanent inhibition of the enzymes. This implies that the greater the inflammatory response, and the more inflamed the synovial membrane, the better will be the transfer of $\alpha_{2}$ MG and the more efficiently the inhibitors can work. A highly inflamed joint should therefore have a higher protective potential against cartilage erosion than a less inflamed one. 
The mechanisms described above show that $\alpha_{1} \mathrm{AT}$ and, presumably, other proteolytic enzyme inhibitors are at a severe physicochemical disadvantage in the immediate vicinity of the cartilage surface. Conversely the production of proteolytic enzymes is enhanced by the presence of cartilage, and enzyme penetration into the cartilage is rapid. The apparent inhibitor excess in synovial fluid therefore may be illusory and measure only a part of the fluid well away from the site of the damage taking place. The ratio between enzyme and inhibitor, therefore, may be much more critical than simple synovial fluid estimates would suggest, and the wide differences seen in arthropathies of different erosive potential suggest that there may be a connection between this ratio and joint damage.

Methods for measuring progressive cartilage damage in vivo, however, are not sufficiently sensitive at present to allow this ratio to be used prognostically on an individual basis. But it and the $\beta$-glucuronidase output per 1000 polymorphs are already in use in this unit as additional diagnostic aids in early arthropathies, and their prognostic value is being studied.

I thank Mr Jeffrey Baker for his expert technical assistance and the Arthritis and Rheumatism Council for financial support.

\section{References}

1 Dingle J T. Recent studies on the control of joint damage: the contribution of the Strangeways Research Laboratory. Heberden Oration 1978. Ann Rheum Dis 1979; 38: 201-14.

2 Hadler N M, Johnson A M, Spitznagel J K, Quinet R J. Protease inhibitors in inflammatory synovial effusions. Ann Rheum Dis 1981; 40: 55-9.

3 Zvaifler $\mathrm{N}$. The immunopathology of joint inflammation in rheumatoid arthritis. In Dixon P J, Kunkel H G, eds. Advances in Immunology. New York: Academic Press, 1973; 16: 265-336.

4 Oronsky A, Ignarro L, Perper R. Release of cartilage mucopolysaccharide - degrading neutral protease from human leukocytes. J Exp Med 1973; 138: 461-72.

5 Dingle J T. Articular damage in arthritis and its control. Ann Intern Med 1978; 88: 821-6.

6 Mayer M M. Complement and complement fixation. In Kabat E A, Mayer M M, eds. Experimental immuno-chemistry. 2nd ed. Springfield: Thomas, 1961: 133-240.

7 Laurell C-B, Jeppsson J-O. Protease inhibitors in plasma. In: Putnam F W, ed. The plasma proteins. New York: Academic Press, 1975; 1: 229-64.

8 Laurell C-B. Electroimmunoassay. Scand J Clin Invest 1972; 124 (suppl): 21-37.

9 Fishman W H, Kato K, Anstiss C L, Green S. Human serum $\beta$ glucuronidase: its measurement and some of its properties. Clin Chim Acta 1967; 15: 435.

10 Ekerot L. On protease inhibitors and leukocyte proteases in rheumatoid synovial fluid. Doctoral dissertation. Malmö: Lund University, 1982.

11 Pritchard M H, Nuki G. Gold and penicillamine: a proposed mode of action based on synovial fluid analysis. Ann Rheum Dis 1978; 37: 493-503.

12 Henson $\mathbf{P}$ M. Interaction of cells with immune complexes: adherence, release of constituents and tissue injury. $J$ Exp Med 1971; 134: 114s-33s.

13 Cooke T D, Hurd E R, Jasin H E, Bienenstock J, Ziff M. Identification of immunoglobulins and complement in rheumatoid articular collagenous tissues. Arthritis Rheum 1975; 18: 541-51.

14 Maroudas A. Physicochemical properties of articular cartilage. In: Freeman M A R, ed. Adult articular cartilage. London: Pitman, 1973: 131-70.

15 Janoff A. Granulocyte elastase: role in arthritis and pulmonary emphysema. In: Havermann K, Janoff A, eds. Neutral proteases of human polymorphonuclear leukocytes. Baltimore-Munich: Urban and Schwartzenberg, 1978: 390-417.

16 Ugai K, Ziff M, Jasin H E. Interaction of polymorphonuclear leukocytes with immune complexes trapped in joint collagenous tissues. Arthritis Rheum 1979; 22: 353-64.

17 James H L, Cohen A B. Mechanism of inhibition of porcine elastase by human alpha $a_{1}$ antitrypsin. J Clin Invest 1978; 62: 1344-53.

18 Dean R T. Macrophages as sources of hydrolases and other materials in chronic inflammation. Eur $J$ Rheumatol Inflamm 1979; 3: 11-6.

19 Ohlsson K, Laurell C-B. The disappearance of enzyme-inhibitor complexes from the circulation of man. Clin Sci Mol Med 1976; 51: $87-92$. 